\title{
Wind Tunnel at LABINTHAP (Updated)
}

\author{
Rosas Quiterio Pedro, Toledo Velázquez Miguel, Tolentino Eslava Guilibaldo, \\ Tolentino Eslava René, Sánchez Silva Florencio, Abugaber Francis Juan \\ Researching and Graduate Section, Applied Hydraulics and Thermal Engineering Laboratory, \\ Professional Unit “Adolfo López Mateos", Col. Lindavista, México, D.F. \\ E-mail:mtv49@yahoo.com
}

Received June 29, 2011; revised July 29, 2011; accepted August 13, 2011

\begin{abstract}
Flow behavior in the Thermal Engineering and Applied Hydraulics Laboratory (LABINTHAP) wind tunnel was investigated by measuring the velocity profiles, turbulence intensity and wall effects with a hot wire anemometer. Measurements were carried out under wind speeds 5,15 and $30 \mathrm{~m} / \mathrm{s}$ in planes located at 1.8, 2.6 and $3.4 \mathrm{~m}$ from flow inlet to the test section. The flow showed a good quality with a velocity variation less than $1 \%$, turbulence intensity lower than $4 \%$ and the wall effects allow having an excellent work area in the test section for the velocities evaluated.
\end{abstract}

Keywords: Wind Tunnel, Calibration, Measurement, Boundary Layer, Hot Wire Anemometer

\section{Introduction}

The original LABINTHAP wind tunnel configuration from National Polytechnic Institute (IPN) is shown in Figure 1. The wind tunnel was put into service in 1990; it has not had the capability to be used for accurate measurements due to the flow uniformity and high turbulence intensity in the test section. First works conducted in this facility were flow visualization [1], boundary layer measurement in different geometries and turbomachinery investigation.

This facility is an open circuit wind tunnel with a suction and pressure test section. The airflow is generated by a centrifugal fan driven by a $74.6 \mathrm{~kW}$ electrical motor controlled by a variable frequency drives, to get different velocities in both test sections. The highest wind velocity in the suction test section is $75 \mathrm{~m} / \mathrm{s}$. This velocity depends on environmental temperature, pressure and humidity registered while tests were being carried out.

The test section has a rectangular cross section of 0.8 $\mathrm{m}$ by $0.6 \mathrm{~m}$, a variable length of $5.0 \mathrm{~m}$. The flow inlet was a bellmouth designed in accordance to AMCA standards (AMCA 1987), before and after this device there were two screens to reduce the velocity fluctuation in the test section.

Recent flow measurement in the low speed wind tunnel demonstrated that the velocity variations in the test section were about $2 \%$ and the turbulence intensity was $6.5 \%$ [2], this parameters showed the poor quality of the facility. The Laboratory has undertaken to modify the wind tunnel to improve the flow quality in the test section and get accurate measurements.

The modifications carried out were the design of a contraction nozzle with an area ratio of 9, five stainless

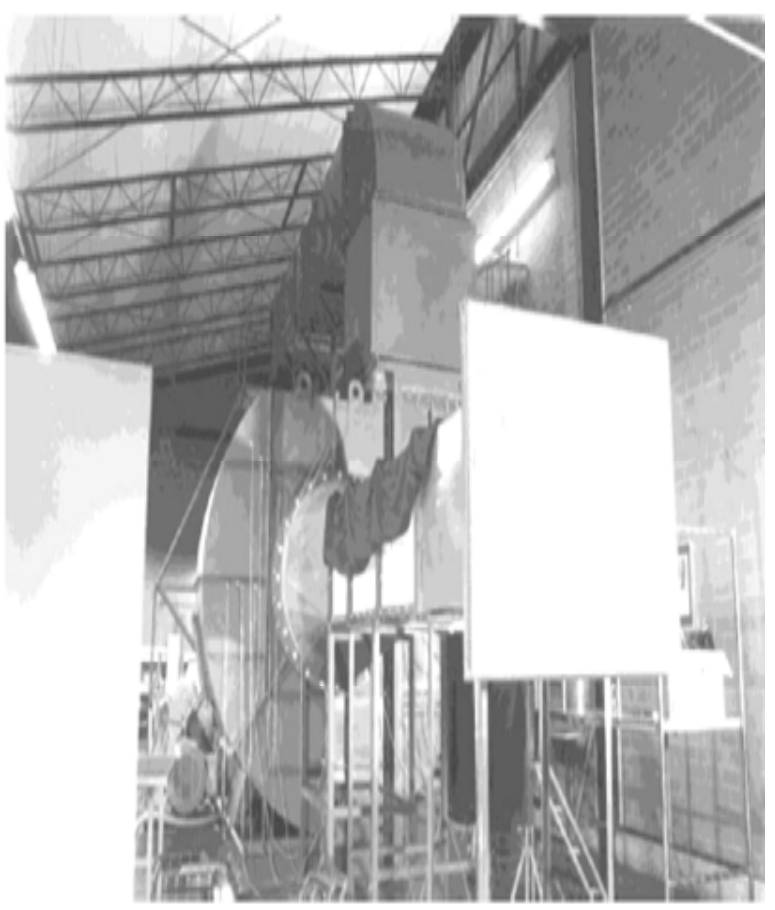

Figure 1. Original wind tunnel configuration. 
steel screens, a honeycomb and a bellmouth at the beginning of the settling chamber, as can be seen in [1]. The aim of this work is to present the modifications of the wind tunnel and, the preliminary flow evaluation of the LABINTHAP wind tunnel with the contraction nozzle only by means of velocity and turbulence profiles and, effect walls.

\section{Methodology}

\subsection{Wind Tunnel Modifications}

Modifications proposed to improve flow quality in the wind tunnel test section are in accordance with the papers developed by Bradshaw P. and Pankhurst R. C., 1964 [3] and Metha R. D. and Bradshaw P., 1979 [4].

\subsection{Screens and Honeycombs}

Screens objectives are reducing the velocity fluctuations in axial direction and making the velocity profile more uniform by a static pressure drop. Reference [3] suggested use four screens with an open area ratio of $\beta>$ 0.57 and the distance between screens have to be of 500 $\mathrm{dw}$ (wire diameters). Reference [4] suggested that the distance between the last screen and the contraction inlet has to be about 0.2 diameters of the settling chamber.

According to previous criterions, five stainless steel screens of 20 meshes will be installed in the wind tunnel settling chamber, wire diameter of $0.23 \mathrm{~mm}$ and an open area ratio of 0.67 . The distance between the last screen and the contraction will be of $500 \mathrm{~mm}$ and, the separations between screens will be of $120 \mathrm{~mm}(521 \mathrm{dw})$.

Honeycombs are effective to remove swirl and lateral mean velocity variations, as long as the flow yaw angles are not greater than $10^{\circ}$ [5]. The design parameters for honeycomb are length to diameter ratio and porosity. The cell length should be about 6 to 8 times its diameter, as mentioned in [4]. The honeycomb that will be installed in the wind tunnel settling chamber will have a cell size of $10.5 \mathrm{~mm}$, thickness of $0.2 \mathrm{~mm}$ and a length of 85 $\mathrm{mm}$.

\subsection{Contraction Nozzle and Bellmouth}

The purposes of contraction nozzle are: a) to increase the mean velocity, b) to reduce velocity variations and c) to reduce velocity fluctuations. The recommended area ratios of the contraction nozzle to get these criterions are 6 to 9 , as mentioned in [4]. The method used to design the contraction nozzle was the one suggested by Morel T., 1977 [6], this method considered an incompressible and no viscous flow. The Morel method use two cubic equa- tions to get the contraction nozzle, both curves are joined in a point $\mathrm{xm}$.

The principal criterions to design the contraction nozzle by this method are: 1) flow uniformity in the exit nozzle, 2) avoiding flow separation, 3) less contraction length and 4) minimum boundary layer thickness. To avoid flow separation pressure coefficient should be 0.42 at the inlet (Cpi) and 0.1 at the contraction exit (Cpo). These coefficient values let to have a velocity variations profiles less than $2 \%$.

The contraction design has a contraction area ratio of 9:1, a length of $1680 \mathrm{~mm}$. This area ratio was chosen due to the laboratory space conditions. The joint of the cubic equations that form the contraction profiles is $\mathrm{xm}=$ 0.531 . At inlet of the settling chamber there is a bellmounth with a radius of 0.125 of the equivalent diameter of this device $(290 \mathrm{~mm})$.

Figure 2 shows the modifications purposed for the wind tunnel, the flow enters by bellmount, after passes to the settling chamber, where the honeycomb and screens are installed, later the flow passes to the contraction nozzle and, finally the flow goes into the test section. The modifications let to have a velocity variation less than $1 \%$ and turbulence intensity less than $0.5 \%$.

In the wind tunnel has been installed the contraction nozzle manufactured with plywood; Figure 3 illustrates the configuration evaluated in this work.

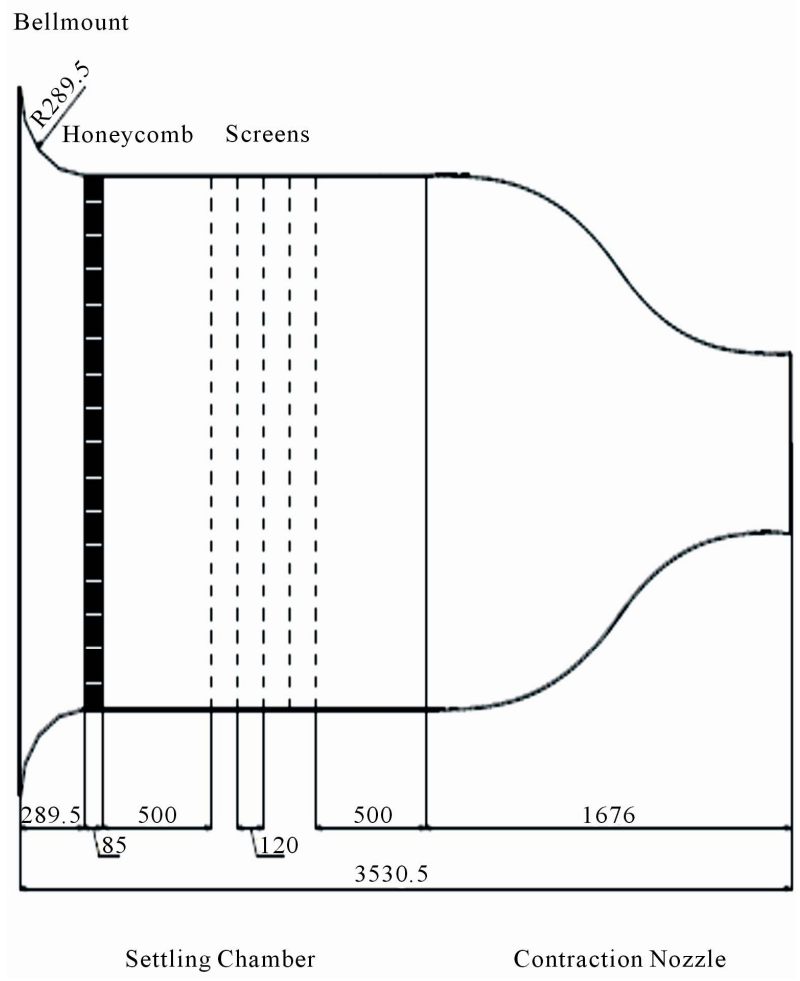

Figure 2. Modification proposed for wind tunnel. 


\subsection{Velocity Profiles Measurement}

The velocity profiles were measured at different locations in the test section; planes were located at 1.8, 2.6 and $3.4 \mathrm{~m}$ from flow inlet as shown in Figure 4. A constant temperature hot wire anemometer was used to measure velocity and turbulence profiles in the test section.

The anemometer used is a DANTEC hot wire anemometer, 90C10 model, and a general purpose probe 55P11. The probe was calibrated in the unit flow of the anemometer and moved by means of a traverse system.

To guarantee the velocity symmetry, a velocity profile was measured in $\mathrm{Y}$ and $\mathrm{Z}$ axis with increments every 5 $\mathrm{cm}$, profiles showed a good flow behavior and are not shown in this work. The velocity profiles were measured only from up and right wall to the center of test section, Figure 4.

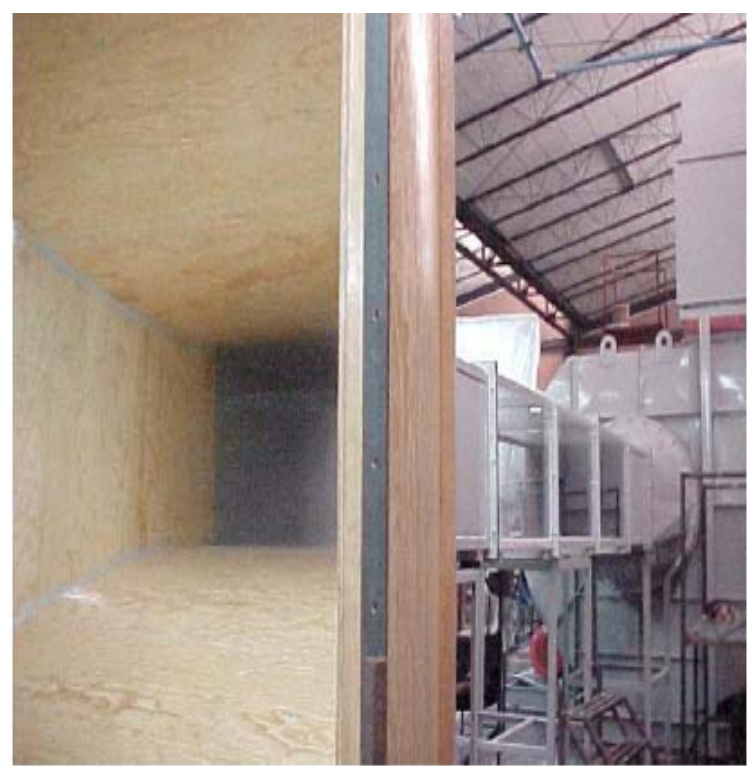

Figure 3. Wind tunnel configuration evaluated.

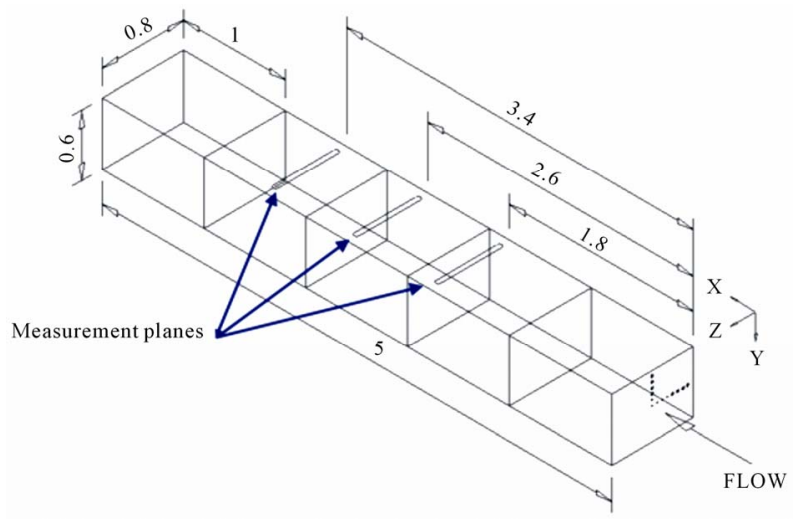

Figure 4. Measurement planes in test section (dim: m).
Velocity and turbulence measurements were carried out with increments every $5 \mathrm{~cm}$, frequency sample of 30 $\mathrm{kHz}$ and a sample time of 30 seconds. Figures 5 to 8 show velocity and turbulence profiles in the first and last plane.

Velocities profiles in $\mathrm{Y}$ and $\mathrm{Z}$ axis (Figures 5 and 6) show that from $5 \mathrm{~cm}$ from both walls these are unaffected for the walls at three velocities evaluated $(5,15$ and $30 \mathrm{~m} / \mathrm{s}$ ) and turbulence intensity are less than $4.5 \%$. Velocity gradients in the free stream zone were less than $1 \%$ for all conditions evaluated in the plane $(X=1.8 \mathrm{~m})$.

In both axes, turbulence intensity values were the highest in the first point of measurement near the walls. The turbulence in the center of test section was about $4.2 \%$ for the lowest velocity $(5 \mathrm{~m} / \mathrm{s})$. For velocities of 15 $\mathrm{m} / \mathrm{s}$ and $30 \mathrm{~m} / \mathrm{s}$ the turbulence intensity in the test section center was about 3.2\% as shown in Figures 5 and 6. For

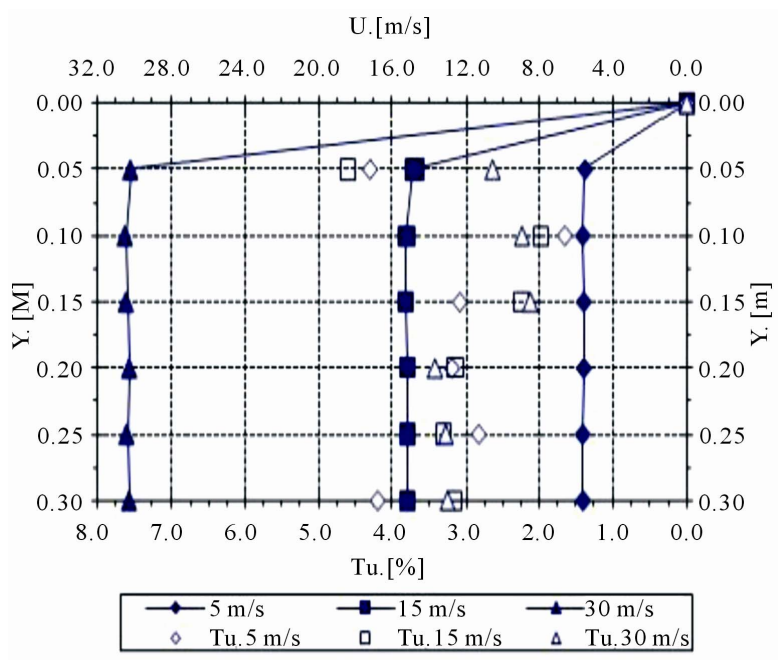

Figure 5. Velocity and turbulence profiles axis $Y, 1.8 \mathrm{~m}$.

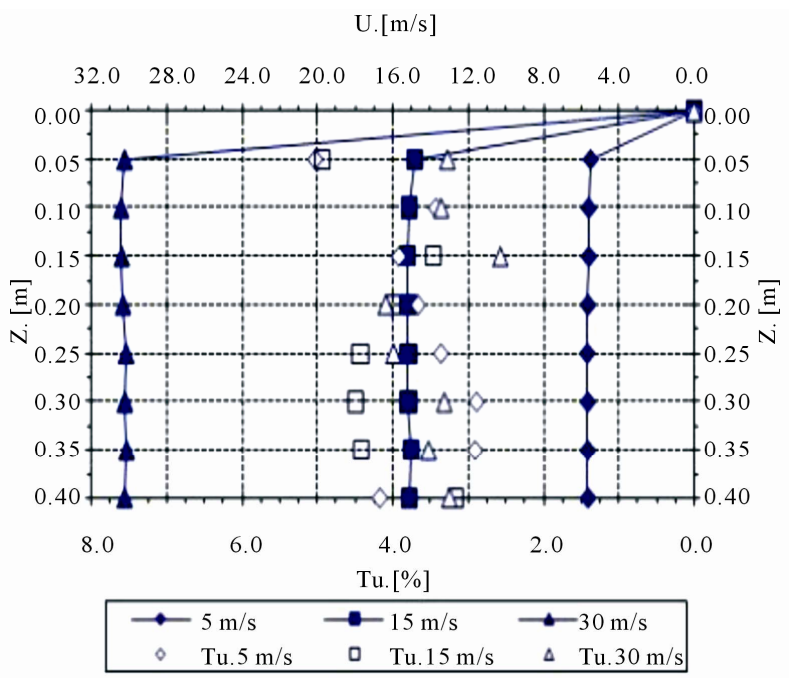

Figure 6. Velocity and turbulence profiles axis $\mathrm{Z}, 1.8 \mathrm{~m}$. 
the velocity of $15 \mathrm{~m} / \mathrm{s}$ the turbulence intensity is about $5 \%$ from 25 to $35 \mathrm{~cm}$ from right wall, Figure 6 .

In last measurement plane $(\mathrm{X}=3.4 \mathrm{~m})$, the free stream velocity is reached at $15 \mathrm{~cm}$ from the up wall for $30 \mathrm{~m} / \mathrm{s}$. For velocities of $15 \mathrm{~m} / \mathrm{s}$ and $5 \mathrm{~m} / \mathrm{s}$, free stream velocities are gotten at $10 \mathrm{~cm}$ from the wall, Figure 7 . Velocity variation in the free stream zone is less than $1 \%$. Turbulence intensity is about $10 \%$ in the first point $(5 \mathrm{~cm}$ from the wall) and turbulence intensity in the center of test section is less than $3.5 \%$.

Velocity profiles illustrate the wall effects at $30 \mathrm{~m} / \mathrm{s}$ in this condition the free stream is gotten at $15 \mathrm{~cm}$ from the wall, at $15 \mathrm{~m} / \mathrm{s}$ is gotten at $10 \mathrm{~cm}$ from wall and, at lowest velocity is gotten at $5 \mathrm{~cm}$. The velocity uniformity is less than $1 \%$ in the free stream zone, Figure 8.

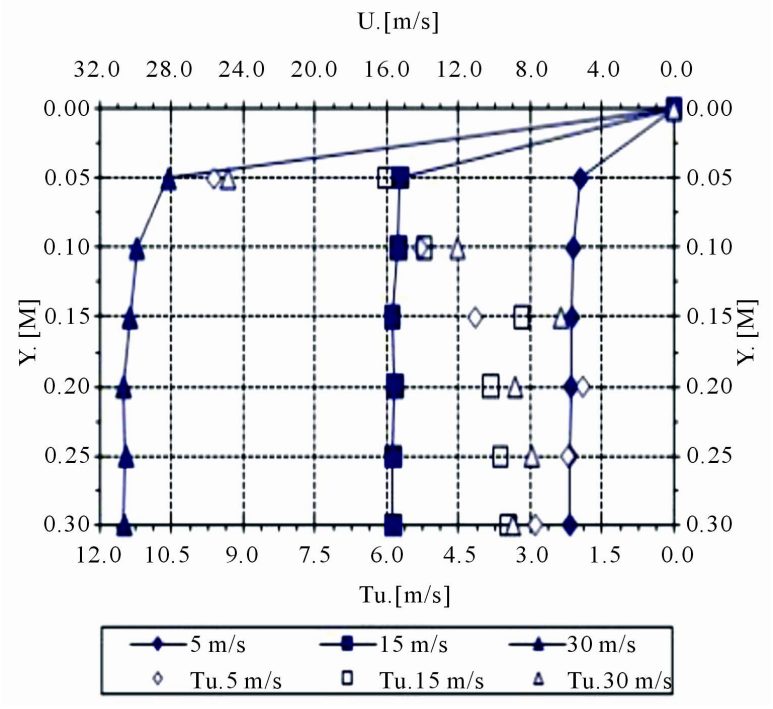

Figure 7. Velocity and turbulence profiles axis $\mathrm{Y}, 3.4 \mathrm{~m}$.

$$
\text { U. }[\mathrm{m} / \mathrm{s}]
$$

$\begin{array}{lllllllll}32.0 & 28.0 & 24.0 & 20.0 & 16.0 & 12.0 & 8.0 & 4.0 & 0.0\end{array}$

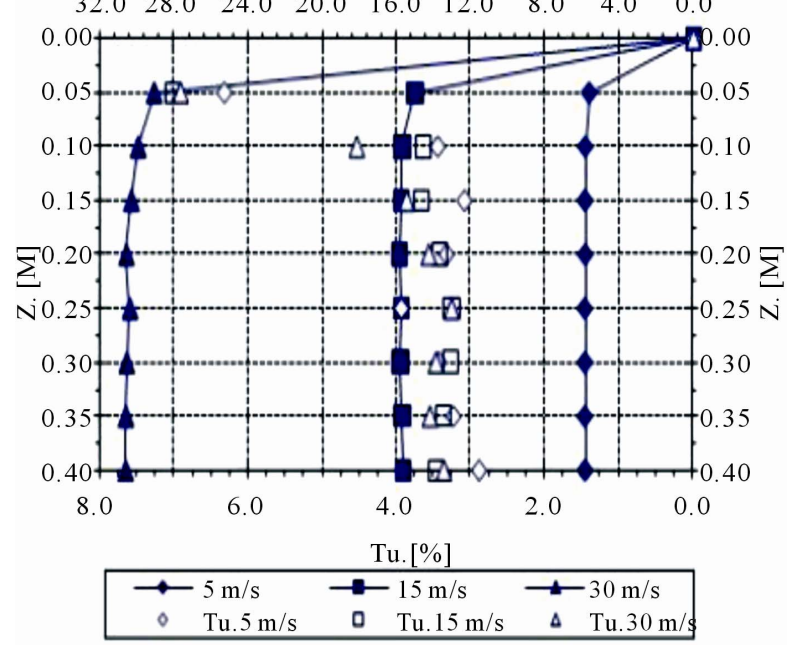

Figure 8. Velocity and turbulence profiles axis Z, $3.4 \mathrm{~m}$.
Figure 8 shows high turbulence intensity in measurements near right wall $(7 \%)$ at three velocity conditions evaluated. For all velocities turbulence intensity is less than $4 \%$ in the free stream zone. Turbulence intensity in test section center is less than $3 \%$ as Figure 8 shows.

Velocities profiles (Figures 5 to 8) show a good flow quality but turbulence intensity is higher, because the set up evaluated only had the contraction nozzle at inlet of flow to the test section. To reduce turbulence and improve velocity uniformity in the test section it is necessary to install the settling chamber and the bellmouth.

\subsection{Wall Effects in the Test Section}

Wall effects were investigated by measuring the velocity every $5 \mathrm{~mm}$ up to $200 \mathrm{~mm}$ from wall. Measurements were carried out with 55P15 probe and are presented in Figures 9 and 10.

Frequency and time sample were similar to velocity and turbulence measurement. Wall effects were measured at three planes and velocities evaluated. In this paper

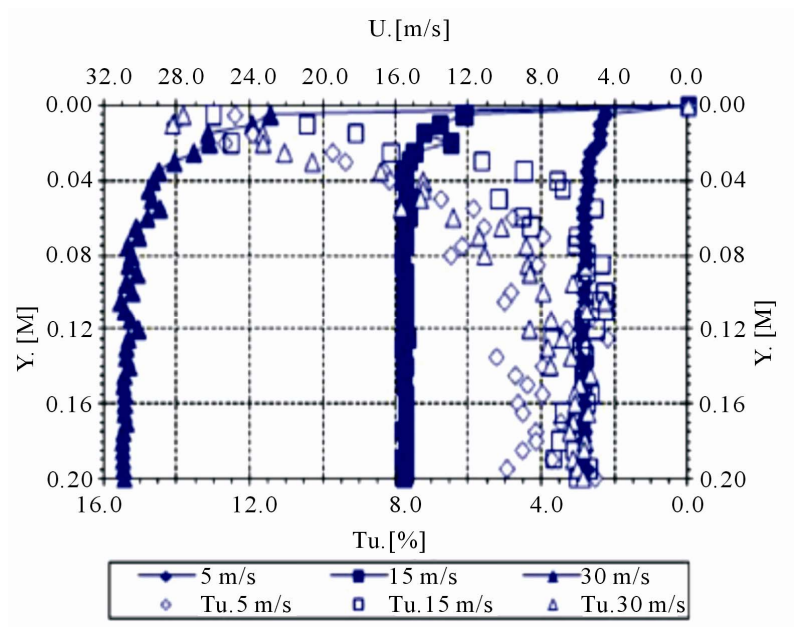

Figure 9. Wall effects in $\mathrm{X}=3.4 \mathrm{~m}$, axis $\mathrm{Y}$.

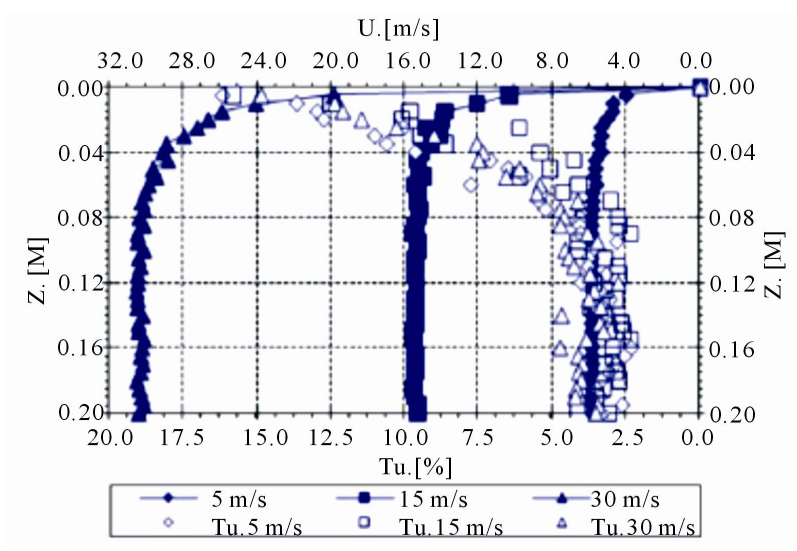

Figure 10. Wall effects in $X=3.4 \mathrm{~m}$, axe $\mathrm{Z}$. 
only the results in axis $\mathrm{Y}$ and $\mathrm{Z}$ at $3.4 \mathrm{~m}$ from flow inlet to test section are shown. From wall effects measurement boundary layer thickness was obtained in upper and right walls for all conditions evaluated, Table 1.

Figure 9 shows that free stream velocity in axis $\mathrm{Y}$ is gotten at $0.075 \mathrm{~m}, 0.065 \mathrm{~m}$ and $0.045 \mathrm{~m}$ for $30 \mathrm{~m} / \mathrm{s}, 15$ $\mathrm{m} / \mathrm{s}$ and $5 \mathrm{~m} / \mathrm{s}$ respectively. Figure 10 presents the wall effects in $\mathrm{Z}$ axe; free stream velocity is gotten at $0.07 \mathrm{~m}$ $(30 \mathrm{~m} / \mathrm{s}), 0.06 \mathrm{~m}(15 \mathrm{~m} / \mathrm{s})$ and $0.05 \mathrm{~m} .(5 \mathrm{~m} / \mathrm{s})$ from right wall. The velocity variations in the free stream zone are less than $2 \%$ for all conditions measured.

From wall effects measurements, it is observed that turbulence intensity is higher in the measurements from $0.0 \mathrm{~m}$ to $0.08 \mathrm{~m}$, in axis $\mathrm{Y}$ and $\mathrm{Z}$, and has values from $12 \%$ to $16 \%$. Turbulence reduces its value to free stream zone where it is less than $4.5 \%$ for all conditions evaluated.

Velocity profiles and effects in walls measurements in the low speed wind tunnel section allow to establish the work section in a range from $5 \mathrm{~m} / \mathrm{s}$ to $30 \mathrm{~m} / \mathrm{s}$ in the three planes evaluated.

\subsection{Work Window in Test Section}

The boundary layer thickness gotten from wall effects measurement allow to obtain the work section dimensions for all velocity conditions in the three planes evaluated. In this work only the development of work section in the tree planes for highest velocity evaluated $(30 \mathrm{~m} / \mathrm{s})$ is presented. Figure 11 shows the work window for this condition.

Boundary layer thickness gotten in up and right walls were considered symmetric for the down and left walls. The previous assumption let to have the work section dimensions for $30 \mathrm{~m} / \mathrm{s}$, in the first plane $(1.8 \mathrm{~m})$ the dimensions are $0.52 \mathrm{~m}$ by $0.69 \mathrm{~m}$; at $2.6 \mathrm{~m}$ from flow inlet free stream zone is $0.47 \mathrm{~m}$ by $0.68 \mathrm{~m}$; and in the last plane located at $3.4 \mathrm{~m}$ from nozzle exit is $0.45 \mathrm{~m}$ by 0.66 as shown in Figure 11. The atmospheric pressure is a function of the altitude. In accordance with the definition of static pressure, the following differential equation is obtained.

To carry out the characterization of the test section LABINTHAP lower speed wind tunnel test section in

Table 1. Test section boundary layer thickness.

\begin{tabular}{ccccccc}
\hline \multirow{2}{*}{$\mathrm{X}[\mathrm{m}]$} & \multicolumn{2}{c}{$\mathrm{U}_{\infty}=5.5 \mathrm{~m} / \mathrm{s}$} & \multicolumn{2}{c}{$\mathrm{U}_{\infty}=15.3 \mathrm{~m} / \mathrm{s}$} & \multicolumn{2}{c}{$\mathrm{U}_{\infty}=30.7 \mathrm{~m} / \mathrm{s}$} \\
\cline { 2 - 7 } & $\delta_{\mathrm{Y}}[\mathrm{mm}]$ & $\delta_{\mathrm{Z}}[\mathrm{mm}]$ & $\delta_{\mathrm{Y}}[\mathrm{mm}]$ & $\delta_{\mathrm{Z}}[\mathrm{mm}]$ & $\delta_{\mathrm{Y}}[\mathrm{mm}]$ & $\delta_{\mathrm{Z}}[\mathrm{mm}]$ \\
\hline 1.8 & 25 & 35 & 35 & 45 & 40 & 55 \\
2.6 & 35 & 45 & 55 & 50 & 65 & 60 \\
3.4 & 45 & 50 & 65 & 60 & 75 & 70 \\
\hline
\end{tabular}

function of the aforementioned parameters, were perfomed a series of measurements with a hot wire anemometer, to determine: frequency $\mathrm{f}$, sample time tand $\mathrm{y}$ number of samples $\mathrm{N}$, for speeds of $5 \mathrm{~m} / \mathrm{s}, 10 \mathrm{~m} / \mathrm{s}, 15 \mathrm{~m} / \mathrm{s}, 20$ $\mathrm{m} / \mathrm{s}, 25 \mathrm{~m} / \mathrm{s}$ and $30 \mathrm{~m} / \mathrm{s}$. Measurements were made in the center of the wind tunnel test section at a distance of 1.6 $\mathrm{m}$ to the start of the test section looking for turbulence levels, frequencies and optimal sampling times. To obtain these measurements it was used a general purpose probe 55P11 mark.

In Figures 12 and $\mathbf{1 3}$ it shows that the turbulence is stabilized as from the $15 \mathrm{kHz}$ and the sampling time becomes unstable after $50 \mathrm{~s}$ for the critical speed $5 \mathrm{~m} / \mathrm{s}$ and $30 \mathrm{~m} / \mathrm{s}$, whereby it was established that the optimal sampling frequency for the development of the experimental phase of this work was $30 \mathrm{kHz}$ and a sampling time of 30 s, so it was obtained a sample of 900,000 data for each punctual speed measurement was made.

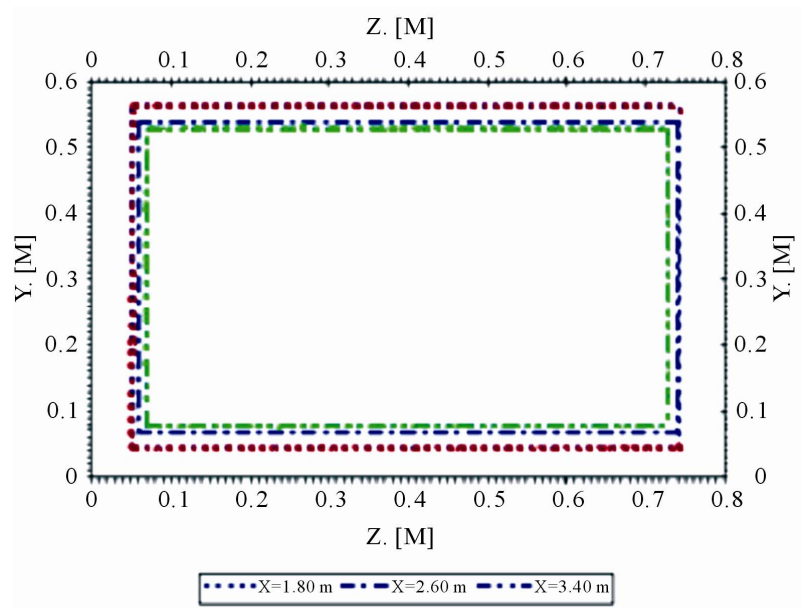

Figure 11. Work section at $30 \mathrm{~m} / \mathrm{s}$ in $X=3.4 \mathrm{~m}$.

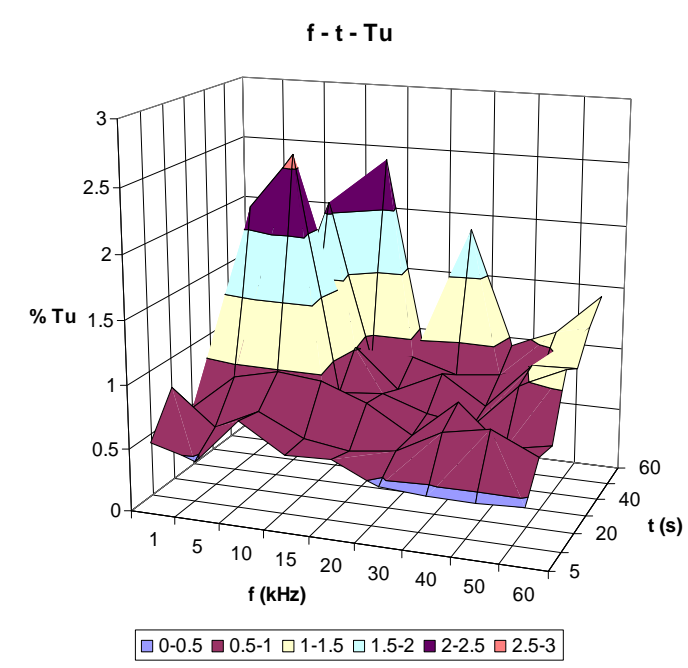

Figure 12. Turbulence at different frequencies and sampling time of $5 \mathrm{~m} / \mathrm{s}$. 
According to experimental approaches, the first part of the characterization was carried out by measuring the velocity profiles at $\mathrm{X}=0.8 \mathrm{~m}, \mathrm{X}=1.6 \mathrm{~m} \mathrm{X}=2.4 \mathrm{~m}$ for speeds of $5 \mathrm{~m} / \mathrm{s}, 10 \mathrm{~m} / \mathrm{s}, 15 \mathrm{~m} / \mathrm{s}, 20 \mathrm{~m} / \mathrm{s}, 25 \mathrm{~m} / \mathrm{s}$ and 30 $\mathrm{m} / \mathrm{s}$ in the $\mathrm{Y}$ and $\mathrm{Z}$ axes, making a sweep every $0.05 \mathrm{~m}$ on the axes mentioned. Figures 14-16 shows the velocity profiles measured with hot wire anemometer at $\mathrm{X}=0.8$ $\mathrm{m}, \mathrm{X}=1.6 \mathrm{~m}, \mathrm{X}=2.4 \mathrm{~m}$ respectively.

According to experimental approaches, the second part of the characterization was carried out by measuring the boundary layer at $\mathrm{X}=0.8 \mathrm{~m}, \mathrm{X}=1.6 \mathrm{~m} \mathrm{X}=2.4 \mathrm{~m}$ for speeds of $5 \mathrm{~m} / \mathrm{s}, 10 \mathrm{~m} / \mathrm{s}, 15 \mathrm{~m} / \mathrm{s}, 20 \mathrm{~m} / \mathrm{s}, 25 \mathrm{~m} / \mathrm{s}$ and $30 \mathrm{~m} / \mathrm{s}$ in the $\mathrm{Y}$ and $\mathrm{Z}$ axes, making a sweep in each of these axes $0.05 \mathrm{~m}$.

Figures 17-19 shows the velocity profiles obtained with hot wire anemometer $\mathrm{X}=0.8 \mathrm{~m}, \mathrm{X}=1.6 \mathrm{~m}, \mathrm{X}=2.4$ $\mathrm{m}$ respectively. To determine the velocity profiles a boundary layer probe 55P15, Dantec was used.

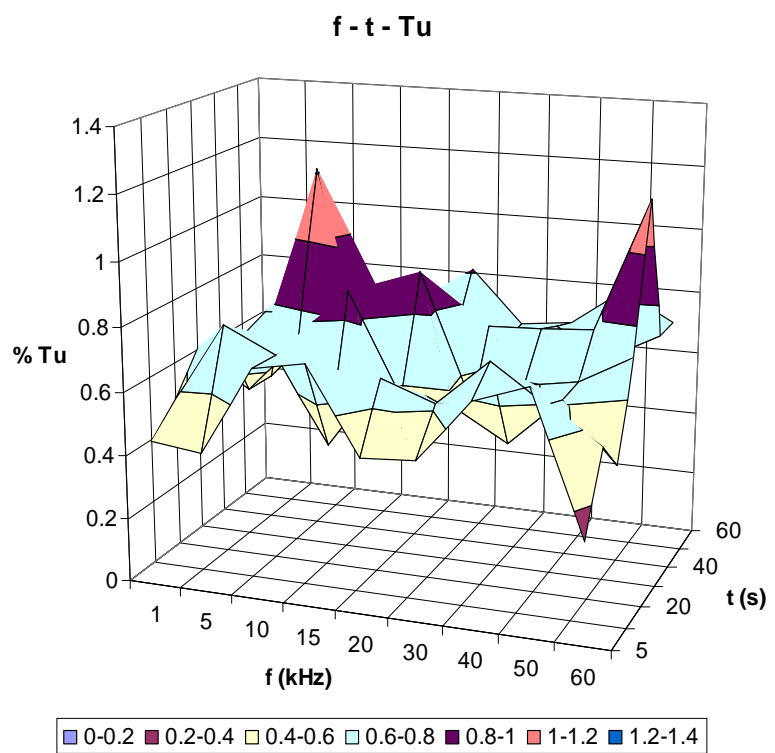

Figure 13. Velocity profiles.

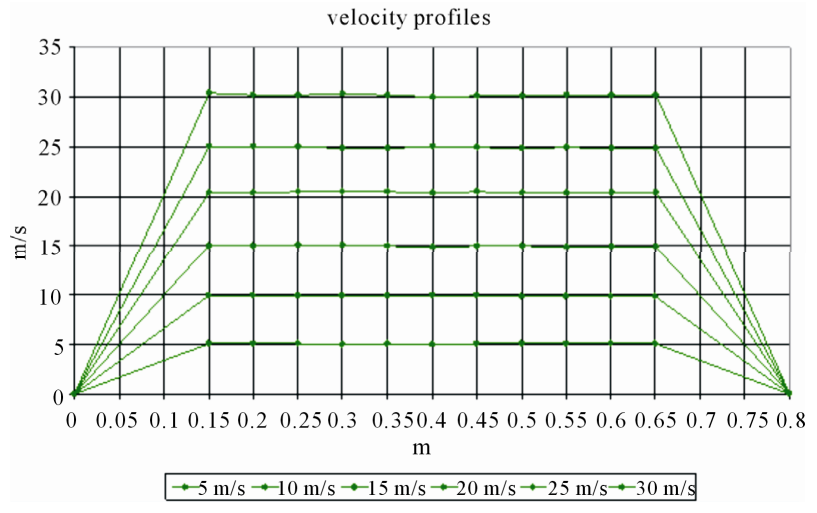

Figure 14. Velocity profiles in the $\mathrm{Z}$ axis in the plane of $\mathbf{0 . 8}$ m.

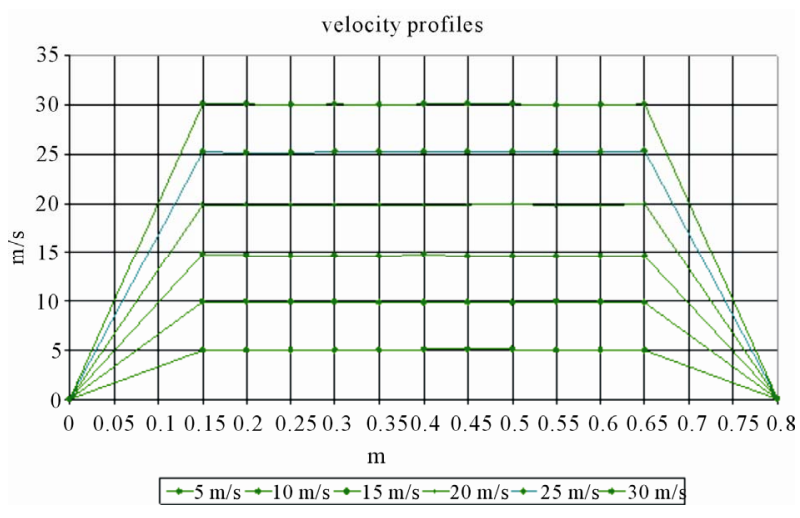

Figure 15. Velocity profiles in the $\mathrm{Z}$ axis in the plane of $1.6 \mathrm{~m}$.

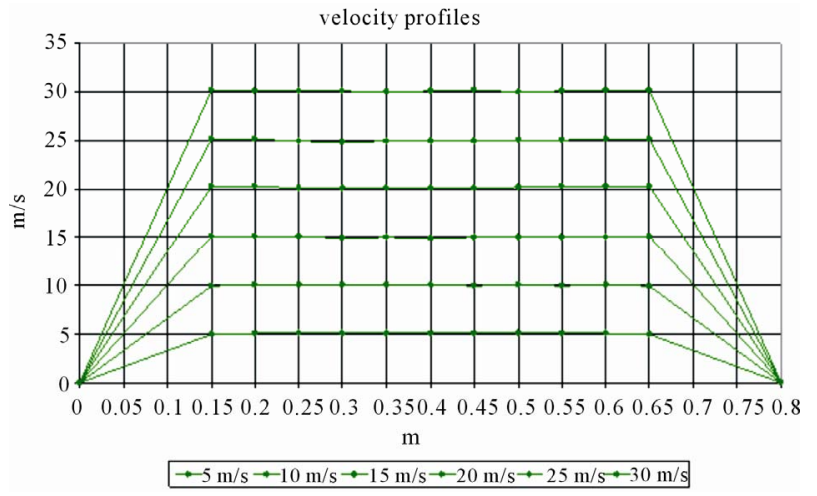

Figure 16. Velocity profiles in the $\mathrm{Z}$ axis in the plane of $2.4 \mathrm{~m}$.

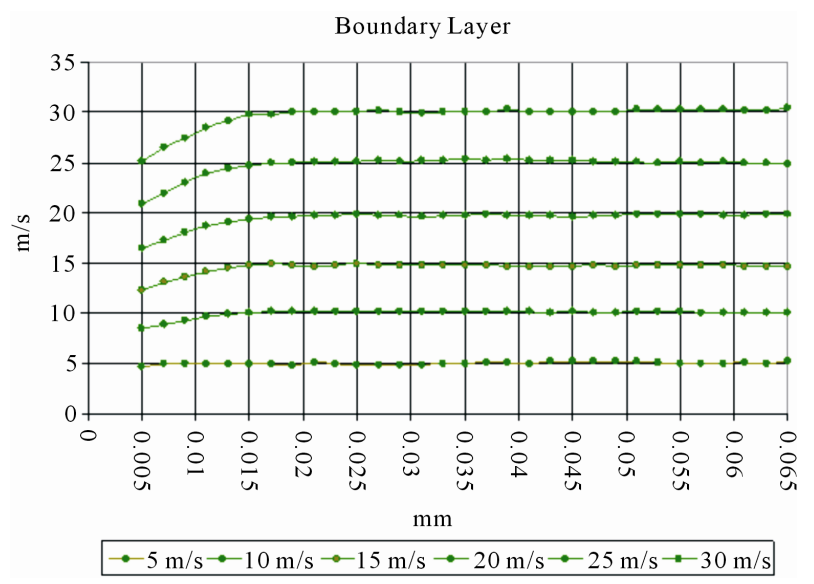

Figure 17. Boundary layer in the $X$ axis, in the plane at $0.8 \mathrm{~m}$.

\subsection{Turbulence}

According to experimental approaches, the third part of the charaterization was carried out by measuring the level of turbulence in $X=0.8 \mathrm{~m}, \mathrm{X}=1.6 \mathrm{~m}, \mathrm{X}=2.4 \mathrm{~m}$ for the range of speed from $5 \mathrm{~m} / \mathrm{s}$ to $30 \mathrm{~m} / \mathrm{s}$ in the center of the calibration zone.

The Figure 20 shows the turbulence levels obtained with the hot wire anemometer $\mathrm{X}=1.6 \mathrm{~m}$. To determine 
Boundary Layer

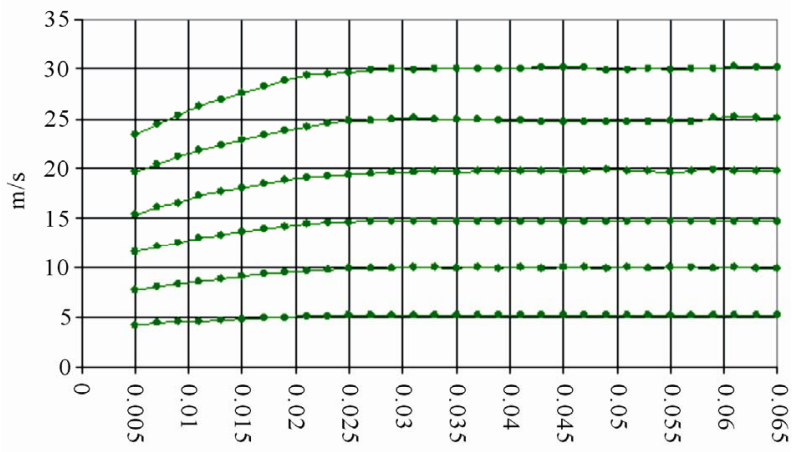

$\mathrm{mm}$ $\rightarrow-5 \mathrm{~m} / \mathrm{s} \rightarrow-10 \mathrm{~m} / \mathrm{s} \rightarrow-15 \mathrm{~m} / \mathrm{s} \rightarrow-20 \mathrm{~m} / \mathrm{s} \rightarrow-25 \mathrm{~m} / \mathrm{s} \rightarrow 30 \mathrm{~m} / \mathrm{s}$

Figure 18. Boundary layer in the $X$ axis, in the plane at $1.6 \mathbf{~ m}$.

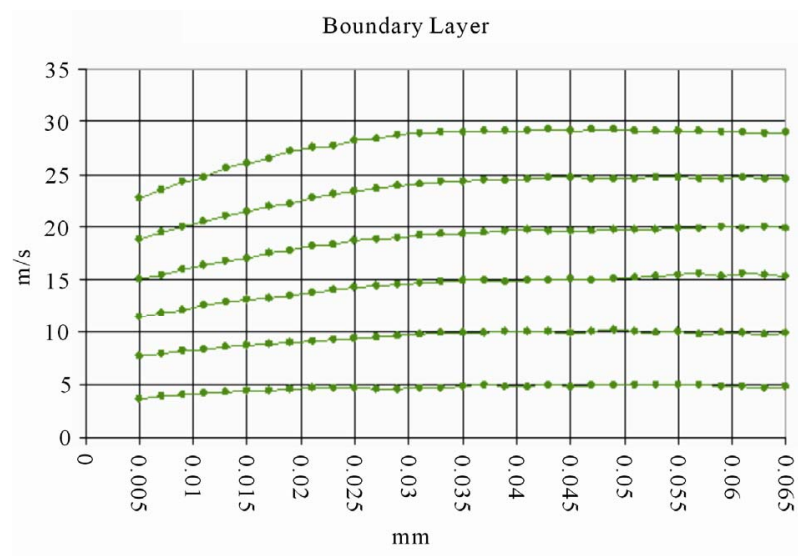

$-5 \mathrm{~m} / \mathrm{s} \rightarrow-10 \mathrm{~m} / \mathrm{s} \rightarrow-15 \mathrm{~m} / \mathrm{s} \rightarrow-20 \mathrm{~m} / \mathrm{s} \rightarrow-25 \mathrm{~m} / \mathrm{s} \rightarrow-30 \mathrm{~m} / \mathrm{s}$

Figure 19. Boundary layer in the $X$ axis, in the plane at $2.4 \mathbf{m}$.

U vs TU

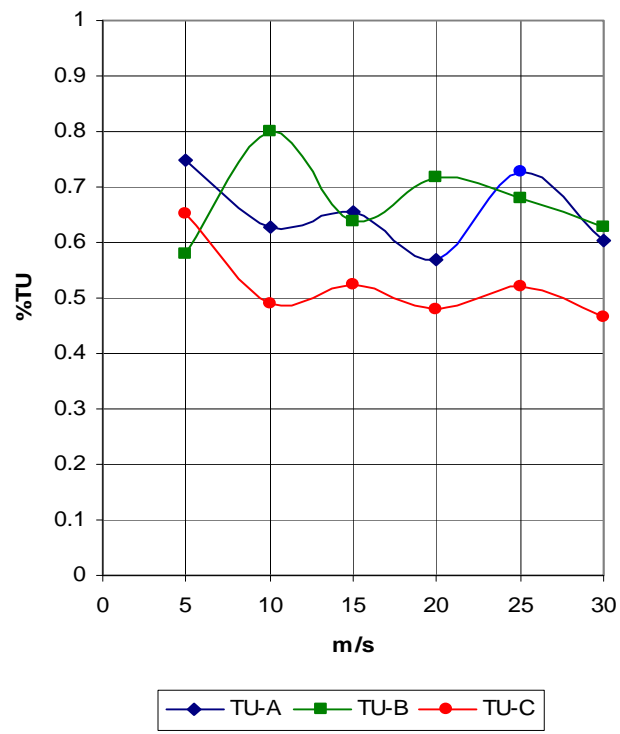

Figure 20. Turbulence against speed. the velocity profiles it was used a general purpose probe 55P11, Dantec brand, which was placed with its support parallel to the flow, leaving the sensor perpendicular to the main flow and as close as possible to the wall.

\subsection{Flow in Corners}

According to experimental methodology, the final part of the characterization was carried out by measuring the flow in corners at $0.8 \mathrm{~m}, 1.6 \mathrm{~m}$ and $2.4 \mathrm{~m}$ for the range of speed from $5 \mathrm{~m} / \mathrm{s}$ to $30 \mathrm{~m} / \mathrm{s}$ as shown in Figure 21 .

To carry out the measurement of flow in the corners it was realized a sweep in the $\mathrm{Y}$ and $\mathrm{Z}$ axes, simultaneously. The sweep was divided into two cross sections, the first at each $0.03 \mathrm{~m}$ in those axes.

\section{Analysis of Results}

This chapter shows the analysis of results of this work, in which were made the measurements of velocity profiles, boundary layer thickness, and flow turbulence level in corners, all in order to determine the area calibration.

\subsection{Speed Profiles}

About velocity profiles, we can conclude that the level of fluctuation in the profiles decreased satisfactorily, as can be seen in Figures 22 and 23, corresponding to the $\mathrm{Z}$ and $\mathrm{Y}$ axes and Tables 2 and 3, respectively.

\subsection{Turbulence}

In the turbulence intensity can conclude that fulfilled one of the main objectives of this work, which was to reduce the level of turbulence (Table 4) to reach the level of turbulence required by CENAM. In Figure 24 we can

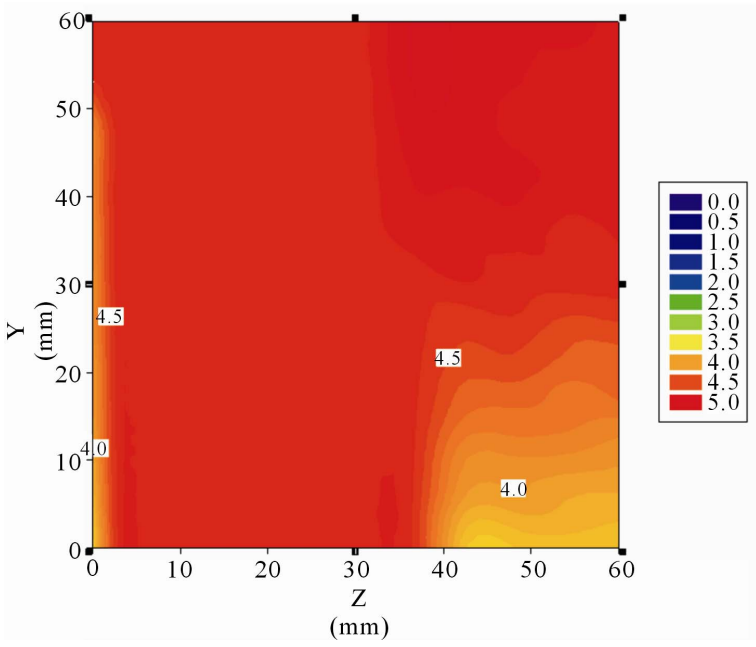

Figure 21. Corner flow in the plane at $2.4 \mathrm{~m}$. 


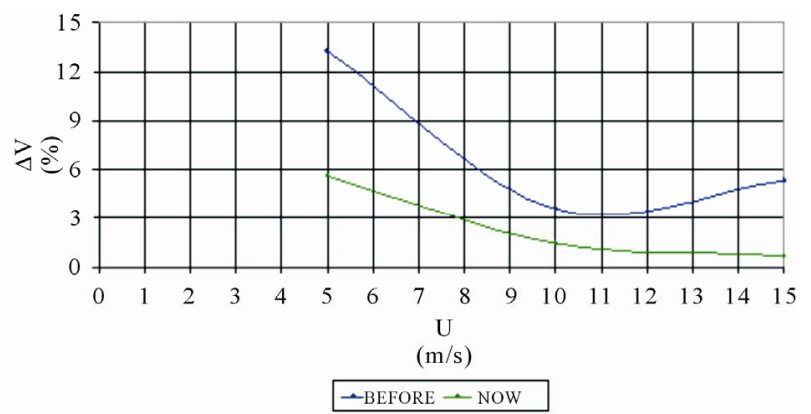

Figure 22. Boundary Layers on the $X$ axis in the plane at $0.8 \mathrm{~m}$.

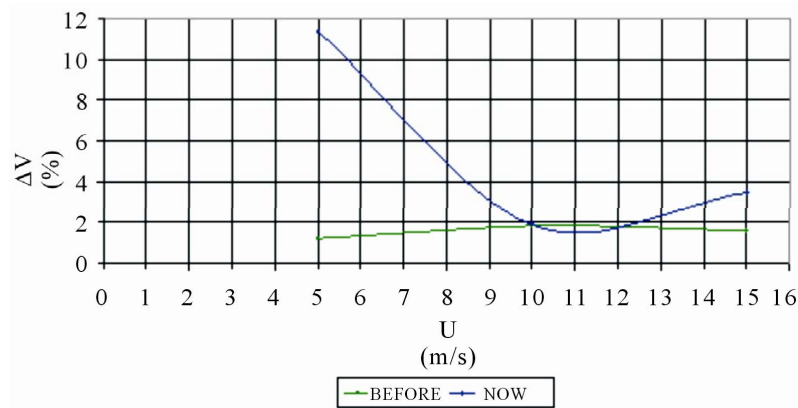

Figure 23. Boundary Layers on the $X$ axis in the plane at $0.8 \mathrm{~m}$.

Table 2. Uniformity of speed profiles before and after changes in $X=1.6 \mathrm{~m}$.

\begin{tabular}{ccccccc}
\hline & AFTER & BEFORE & AFTER & BEFORE & AFTER & BEFORE \\
\hline $\mathrm{Z}$ & $\mathrm{U}_{5}$ & $\mathrm{U}_{5}$ & $\mathrm{U}_{15}$ & $\mathrm{U}_{15}$ & $\mathrm{U}_{30}$ & $\mathrm{U}_{30}$ \\
$(\mathrm{~m})$ & $(\mathrm{m} / \mathrm{s})$ & $(\mathrm{m} / \mathrm{s})$ & $(\mathrm{m} / \mathrm{s})$ & $(\mathrm{m} / \mathrm{s})$ & $(\mathrm{m} / \mathrm{s})$ & $(\mathrm{m} / \mathrm{s})$ \\
0 & 0 & 0 & 0 & 0 & 0 & 0 \\
0.15 & 5.021 & 5.5815 & 15.07 & 15.2275 & 25.02 & 30.2545 \\
0.2 & 5.059 & 5.6475 & 15.07 & 15.1365 & 25.046 & 30.1615 \\
0.25 & 5.065 & 5.654 & 15.094 & 15.1835 & 25.015 & 30.1405 \\
0.3 & 5.068 & 5.6155 & 14.949 & 15.204 & 24.884 & 30.1475 \\
0.35 & 5.059 & 5.652 & 14.979 & 15.142 & 24.854 & 30.074 \\
0.4 & 5.064 & 5.6455 & 14.926 & 15.122 & 25.024 & 30.1405 \\
$\Delta \mathrm{U}(\%)$ & 5.6 & 13.2667 & 1.4667 & 3.5967 & 0.7167 & 5.3033 \\
\hline
\end{tabular}

Table 3. Uniformity of speed profiles before and after changes in $X=1.6 \mathrm{~m}$.

\begin{tabular}{|c|c|c|c|c|c|c|}
\hline & AFTER & BEFORE & AFTER & BEFORE & AFTER & BEFORE \\
\hline $\begin{array}{c}\mathrm{Y} \\
(\mathrm{m})\end{array}$ & $\begin{array}{c}\mathrm{U}_{5} \\
(\mathrm{~m} / \mathrm{s})\end{array}$ & $\begin{array}{c}\mathrm{U}_{5} \\
(\mathrm{~m} / \mathrm{s})\end{array}$ & $\begin{array}{c}\mathrm{U}_{15} \\
(\mathrm{~m} / \mathrm{s})\end{array}$ & $\begin{array}{c}\mathrm{U}_{15} \\
(\mathrm{~m} / \mathrm{s})\end{array}$ & $\begin{array}{c}\mathrm{U}_{30} \\
(\mathrm{~m} / \mathrm{s})\end{array}$ & $\begin{array}{c}\mathrm{U}_{30} \\
(\mathrm{~m} / \mathrm{s})\end{array}$ \\
\hline 0 & 0 & 0 & 0 & 0 & 0 & 0 \\
\hline 0.15 & 5.175 & 5.6165 & 15.015 & 15.2245 & 30.011 & 29.9775 \\
\hline 0.2 & 5.058 & 5.6025 & 15.076 & 15.1615 & 30.067 & 29.9975 \\
\hline 0.25 & 5.11 & 5.5885 & 14.938 & 15.1675 & 29.987 & 30.0235 \\
\hline 0.3 & 5.107 & 5.6455 & 15.044 & 15.122 & 30 & 30.1405 \\
\hline $\mathrm{U}(\%)$ & 1.25 & 11.325 & 1.825 & 1.8875 & 1.625 & 3.475 \\
\hline
\end{tabular}

Table 4. Turbulence at different velocities and different distances $X=1.6$.

\begin{tabular}{|c|c|c|}
\hline $\mathrm{U}$ & & \\
\hline \multirow[t]{2}{*}{$(\mathrm{m} / \mathrm{s})$} & \multicolumn{2}{|c|}{$(\%)$} \\
\hline & AFTER & BEFORE \\
\hline 5 & 0.679 & 3.2 \\
\hline 10 & 0.699 & 3.2 \\
\hline 15 & 0.639 & 4 \\
\hline 20 & 0.717 & 3.4 \\
\hline 25 & 0.679 & 3.5 \\
\hline 30 & 0.727 & 3.5 \\
\hline
\end{tabular}

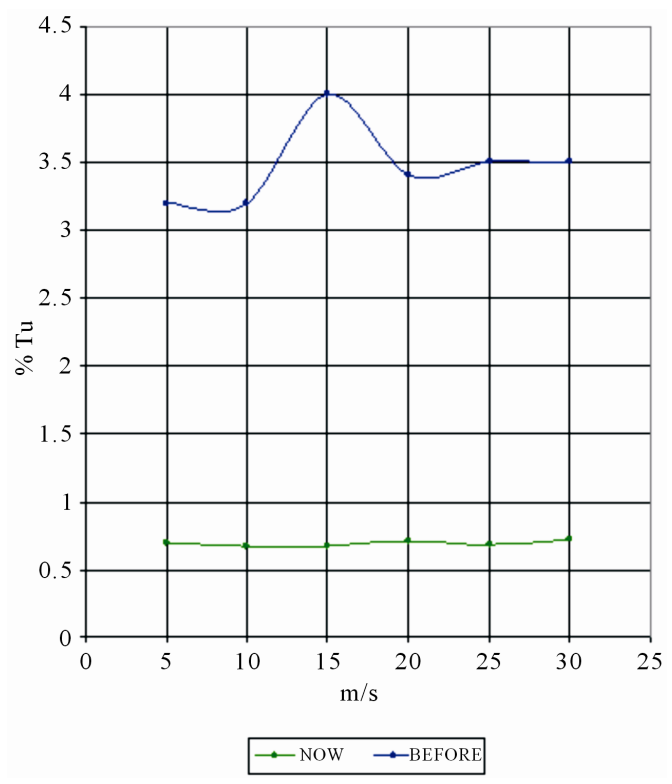

Figure 24. Boundary Layers on the $X$ axis in the plane at $0.8 \mathrm{~m}$.

see the change in the level of turbulence before and after the proposed changes.

We can also note that the sampling time is decreased by $75 \%$ for speeds of $5 \mathrm{~m} / \mathrm{s}$ to $25 \mathrm{~m} / \mathrm{s}$ as well as the sampling rate from 900,000 to 100,000 data, as shown in Figure 25.

Despite this, we have the equation of the Nyquist theorem, which by definition indicates that the sample size should be the square of the wavelength at which the sensor operates.

In Figure 26 it is clear that the level of turbulence has been reduced to less than $1 \%$, so LABINTHAP tunnel is at the level of those who are in countries like Japan, Germany, France, Brazil and USA.

The modifications carried out were the design of a contraction nozzle with an area ratio of 9 , five stainless steel screens, a honeycomb and a bellmouth at the beginning of the settling chamber, as can be seen in [2]. The 


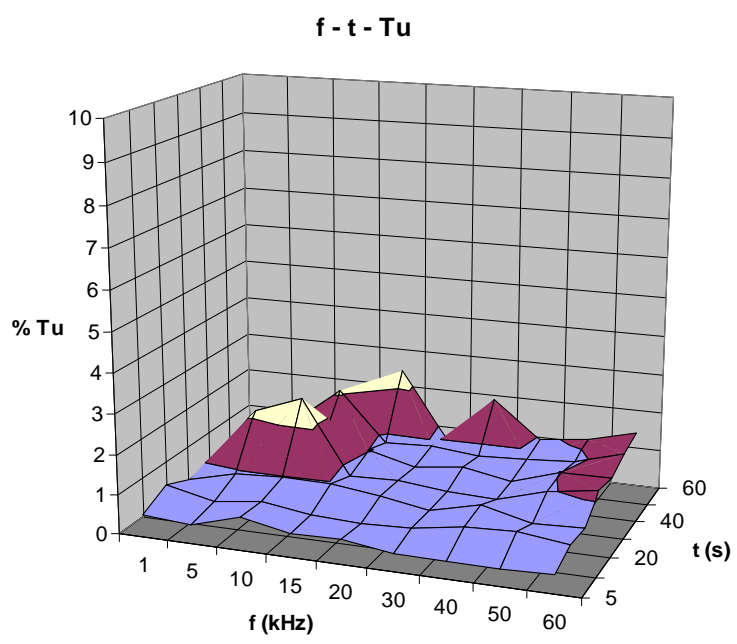

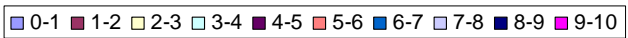

(a)

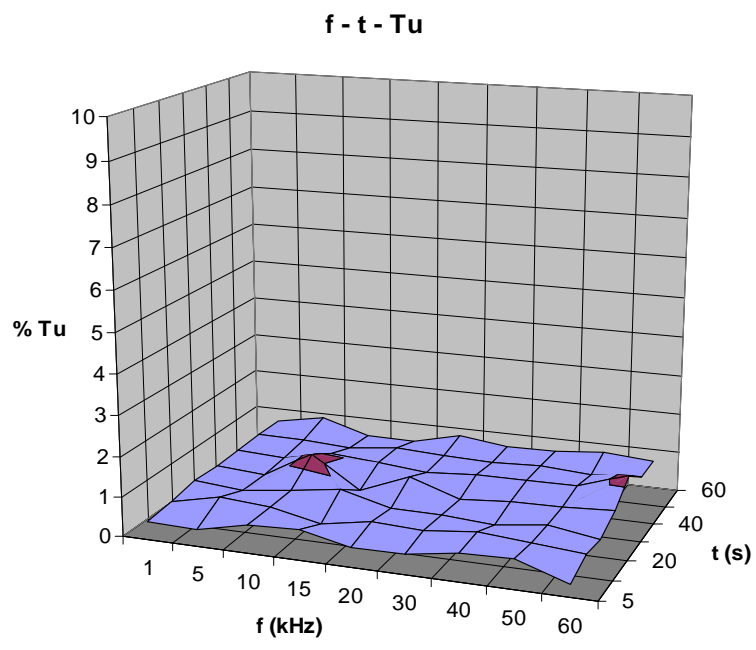

$\square$ 0-1 $\square$ 1-2 $\square$ 2-3 $\square$ 3-4 $\square$ 4-5 $\square$ 5-6 $\square$ 6-7 $\square$ 7-8 घ 8-9 $\square$ 9-10

(b)

Figure 25. (a) Boundary Layers on the $X$ axis in the plane at $0.8 \mathrm{~m}$. (b). Boundary Layers on the $X$ axis in the plane at $0.8 \mathrm{~m}$.

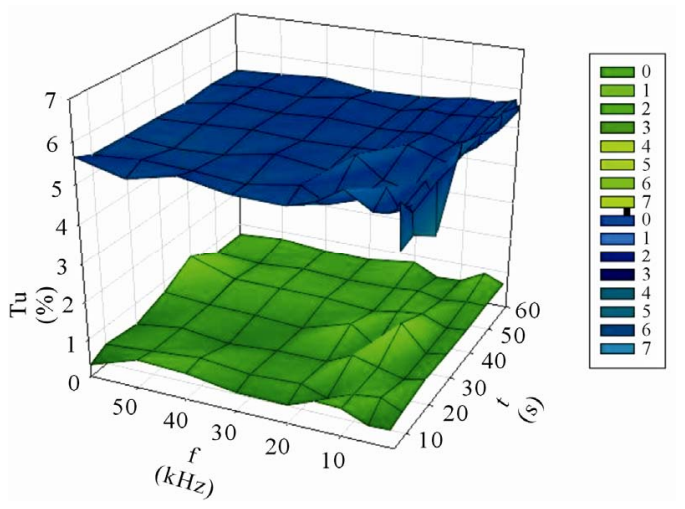

Figure 26. Turbulence level. aim of this work is to present the modifications of the wind tunnel and, the preliminary flow evaluation of the LABINTHAP wind tunnel with the contraction nozzle only by means of velocity and turbulence profiles and, effect walls.

\section{Conclusions}

The low speed wind tunnel test section at LABINTHAP was evaluated by mean of velocity and turbulence profiles, and wall effects for velocities of 5, 15 and $30 \mathrm{~m} / \mathrm{s}$ in planes located at 1.8, 2.6 and $3.4 \mathrm{~m}$ from flow inlet to test section. This is the first evaluation with only the contraction nozzle installed in the test section.

Velocity variations in the free stream inside test section were less than $1 \%$ and turbulence intensity was less than $4.0 \%$ for all conditions evaluated. The contraction nozzles reduce the turbulence intensity from $6.5 \%$ (original configuration) to $4.0 \%$. Nowadays screens and honeycomb are installed to reduce turbulence intensity and improve flow quality in the test section.

Modifications shown in this work reduce turbulence intensity to less than $0.5 \%$ and improve the velocity distribution inside the test section. This allows to do research in fluid dynamics, turbomachinery, boundary layer and airspeed metrology.

\section{References}

[1] G. Tolentino, M. Toledo and V. Zurita, "Experimental Study of Boundary Layer on a NACA 65-010 Blade Using Some Flow Visualization Techniques. Flow Visualization and Imagine Processing of Multiphase System," Proceeding of the 1995 ASME/JSME Fluids Engineering Division Conference, South Carolina, 13-18 August 1995.

[2] E. R. Tolentino, V. M. Toledo, E. G. Tolentino and S. F. Sánchez, "Modificaciones al Túnel de Viento del LABINTHAP para Mediciones de Velocidad de Aire desde $5 \mathrm{~m} / \mathrm{s}$ hasta $30 \mathrm{~m} / \mathrm{s}$," Simposio de Metrología 2004, Querétaro, 25-27 October 2004.

[3] P. Bradshaw and R. C. Pankhurst, "The Design of Low Speed Wind Tunnels," Progress in Aeronautical Sciences, Vol. 5, 1964, pp. 1-69.

[4] R. D. Metha and P. Bradshaw, "Desing Rules for Small Low Speed Wind Tunnels," Aeronautical Journal of the Royal Aeronautical Society, Vol. 73, 1979, pp. 443-449.

[5] J. B. Barlow, W. H. Rae and A. Pope, "Low Speed Wind Tunnel Testing," 3rd Edition, John Wiley and Sons, Hoboken, 1999.

[6] T. Morel, "Design of Two-Dimensional Wind Tunnel Contractions," Journal of Fluids Engineering, Vol. 99, No. 2, 1977, pp. 371-378. http://dx.doi.org/10.1115/1.3448764 